\title{
DEL MODERNISMO A LA VANGUARDIA: EL DIARIO DE UN POETA RECIÉN CASADO
}

\author{
Francisco Javier BLASCO PASCUAL \\ Universidad de Valladolid
}

Se abre el Diario de un poeta recién casado con un lema tomado del sánscrito, que necesariamente tuvo que llenar de perplejidad a los lectores juanramonianos formados en los libros que van de Rimas (1901) a Laberinto (1913). El lema, bajo el título de «Saludo del alba», decía así:

¡Cuida bien de este día! Este día es la vida, la esencia misma de la vida. En su leve transcurso se encierran todas las realidades y todas las variedades de tu existencia: el goce de crecer, la gloria de la acción y el esplendor de la hermosura.

El día de ayer no es sino sueño y el de mañana es sólo una visión. Pero un hoy bien empleado hace de cada ayer un sueño de felicidad y de cada mañana una visión de esperanza. ¡Cuida bien, pues, este día! (Jiménez [1917] 1998, pág. 99).

«Goce de crecer, gloria de la acción y esplendor de la hermosura» dibujan un programa vital -y vitalista-, en el que realmente cuesta reconocer las «variedades de... existencia» de un poeta, a quien, si tenemos en cuenta los libros anteriores a este, nos sería más fácil identificar con la voz que canta las hojas secas, que con la voz que, ahora, frente al «ayer» que «no es sino sueño» y frente al «mañana» que «es sólo una visión», pretende exaltar un «presente», en el que «se encierran todas las realidades». Tras conocer lo que, sobre la historia de la poesía española anterior a la guerra civil, dicen los manuales de literatura, resultaría natural imaginar las palabras de este texto -auténtico manifiesto vanguardista- 
tras las páginas de créditos de un libro que llevase el título -pongo por ejemplode Cántico, pero nos sigue costando trabajo reconocerlas al frente de las seis secciones en que, para respetar las etapas de su viaje a América, el poeta de Moguer divide su Diario. Y, sin embargo, es Juan Ramón, en 1916, y no Guillén, en 1936, quien las hace suyas, sintetizando en ellas toda una poética de la realidad, que significará la ruptura definitiva con el pasado y la inauguración de un tiempo nuevo para su escritura y -lo que es más significativo- para la totalidad de la lírica posterior en lengua española.

Acabo de hablar de vanguardismo y, ciertamente, las vanguardias -o mejor, muchas de las manifestaciones expresivas de la vanguardia- hallan acogida en este libro. Pero no es en esta dirección en la que, ahora, quiero proponer que se lea el Diario. No lo hago, porque creo que el propio Juan Ramón, siempre bien informado de cualquier novedad en poesía, ponía en guardia a sus lectores, desde el prologuillo de la primera edición, ante cualquier posibilidad de equívoco: «No el ansia de color exótico, ni el afán de «necesarias» novedades. La que viaja siempre que viajo, es mi alma entre almas».

El que las «necesarias novedades» no constituyan la clave elegida por el poeta para la lectura de este libro no contradice el hecho de que esta obra haya resultado ser una auténtica novedad en la bibliografía juanramoniana, en primer lugar, y en el universo literario del momento, luego. En efecto, si buscamos algunas palabras que, con cierta precisión, reflejen lo que fue la poesía juanramoniana anterior al Diario, pocas resultan tan exactas como las que Aurora de Albornoz escribe para prologar su magnífica Nueva antolojía. De Rimas, por ejemplo, dice:

Las páginas de Rimas están llenas de «visiones», de «quimeras», de «espectros»... cosa no nueva en nuestra poesía, pero importante dentro de la trayectoria poética de Juan Ramón, que por este camino llegará un poco más tarde a la creación de un mundo auténticamente visionario (Albornoz 1973, pág. 33).

$Y$ en otro lugar añade:

En Arias tristes, Jardines Lejanos o en Pastorales, lo que domina es la presencia de ciertos momentos, en los que el poeta vislumbra en su interior imágenes confusas [y en] que se siente dominado por ritmos inasibles y sentimientos inexplicables (Albornoz 1973, pág. 34).

Un poema de Arias tristes ilustra ejemplarmente el clima descrito por la ilustre estudiosa de Juan Ramón: 


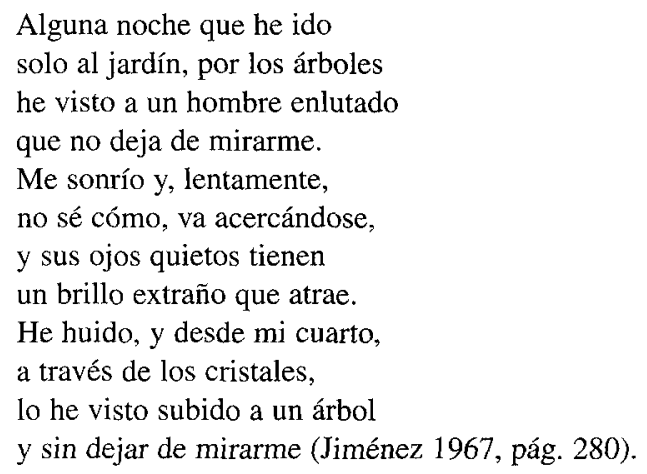

El poeta ha bajado al jardín, pero como le ocurre al personaje de la leyenda becqueriana, no es el jardín lo que ha visto. El jardín, la realidad exterior, no es sino el escenario en el que las visiones y espectros del mundo interior cobran cuerpo. No es al mundo a donde conducen, en su primera época, los poemas de Juan Ramón, sino que conducen -por decirlo con palabras de Schopenhauer-a la representación del mundo en el interior de la conciencia. Y lo que digo de Juan Ramón vale también para los Machado de este mismo momento.

Basta abrir el Diario, por cualquiera de sus páginas, para comprender que algo, que todo, ha cambiado. Así es el amanecer en Nueva York, un día de primavera:

Parece que el cielo se ha roto como un gran huevo fresco y que una yema sorprendente y nunca presumida cuelga por doquiera del inmenso cascarón (Diario CLXXXI).

No escasean, ciertamente, las imágenes visionarias en el Diario, pero la naturaleza de las mismas es muy distinta a las que podemos encontrar en los primeros libros del poeta, porque la poética a que tales imágenes responden es, también, muy distinta. En unas notas, que llevan la fecha de 1942 y que Juan Ramón Jiménez dejó inéditas, el poeta de Moguer afirma del Diario de un poeta recién casado:

La verdadera realización mía de este verso, que había de ser decisiva en mi obra y en la poesía española y americana de su época, me la trajo el mar. En 1916, enero, en el traqueteante tren, camino de Cádiz para embarcarme a América, empecé a escribir unas notas en verso libre que yo consideré provisionales en el primer momento... Al llegar a Cádiz, y ponerlas en limpio en el reposado cuarto del hotel de Francia, comprendí que eran el germen de un nuevo yo poético... 
A estas palabras -tan interesantes- de rememoración de la experiencia estética que da lugar al Diario, siguen otras de reflexión sobre el significado de este singular libro, que también merecen, por el acierto crítico que revelan, un recuerdo:

Inmediatamente después de mi Diario, 1916, este verso desnudo empieza a ser seguido en España... No hay más que ver la lírica española y americana anterior a mi Diario (Darío, Unamuno, Lugones, Antonio Machado, Silva, etc.) y la posterior (Juana de Ibarbourou, Salinas, Neruda, etc.), hasta este curioso estado actual, en que casi nadie escribe más que en este verso mío y, como en lo popular, sin darse cuenta de quién lo dejó en el aire y en la luz de España (Jiménez [1917] 1982, págs. 13-14).

El Diario de un poeta recién casado es un libro clave en la historia de la poesía española del siglo XX. «Después del Diario -ha escrito Ricardo Gullónno se podía seguir escribiendo como antes. Quien así lo hiciera, incurriría en anacronismo, como bien comprendieron los poetas que por aquellos días se aprestaban a entrar en poesía» (Gullón 1982, pág. 12). Quizá puedan citarse, en toda la historia de la poesía española del siglo XX, hasta media docena de libros de igual calidad a la del Diario. Pero no se me ocurre ninguno cuya relevancia histórica, como ruptura con un pasado e inauguración de un futuro que todavía nos alcanza, pueda comparársele. Pensemos un momento, por ejemplo, en Hijos de la ira. El poemario de Dámaso Alonso significó mucho en su momento, al romper, convertida la poesía en grito, con tanta oquedad garcilasista. Pero la estética que este libro - tan valioso en sí mismo y tan necesario en su momento- pone en pie está absolutamente agotada apenas dos décadas más tarde. No ocurre lo mismo con el Diario. El universo al que da vida la palabra junaramoniana del Diario es, con muy pocos cambios, el mismo universo literario en que hoy, casi ochenta años después, nos movemos nosotros sus lectores y en que, lo declaren o lo oculten, se mueve lo más representativo de la lírica actual. Juan Ramón era -como hemos visto- plenamente consciente de la trascendencia de su obra, pero la crítica posterior se ha encargado de demostrar que la apreciación del poeta no era producto de la vana presunción de un creador narcisista. La modernidad del Diario, en esa fecha temprana de 1917, resulta históricamente inexplicable y ciertamente sorprendente. Aunque no menos sorprendente resulta que, ochenta años después, el Diario, por la exactitud de sus hallazgos expresivos, siga apareciéndose al lector de nuestro presente como un libro de extraña y mágica actualidad, antes que como el libro que condensa en sí toda la historia de la poesía del siglo XX.

En efecto, no exagera Aurora de Albornoz (1973), cuando, releyendo el Diario desde la pretensión de comprender lo que la obra juanramoniana «tiene no 
ya de clásica, sino de actual», encuentra en la misma todo un muestrario de técnicas expresivas, en las que, al pasar de los años, vendrá a reconocerse la vanguardia. En este sentido, el Diario, no sólo es un libro de ruptura, sino también un libro de anticipaciones.

Con el Diario se inicia lo mejor de la poesía española contemporánea. Para que los Alberti, Aleixandre, Salinas, Guillén o Cernuda pudieran construir sus respectivos universos poéticos no bastaban los fuegos de artificio de tanta proclama vanguardista. Para que los cohetes bergaminianos resonasen y se hicieran visibles, en una noche despejada de Soledades, de Laberintos y de Melancolías, eran precisas todas las novedades que el Diario trajo a la poesía de su tiempo. El llorado Juan Manuel Rozas supo verlo mejor que ningún otro de los lectores de Juan Ramón:

Con mirada diacrónica, podemos hablar de la poesía española de antes y después del Diario, de modo parecido a como en el Barroco hablamos de antes y después de las Soledades (Rozas 1981, pág. 149).

El propio Juan Manuel Rozas, en una síntesis que me parece ejemplar, ha cifrado en doce puntos las claves en que, según él, toma cuerpo el giro tan singular que con este libro Juan Ramón imprime a la lírica moderna española. Destaco algunos puntos del esquema de Rozas:

«1.- Ese claro deseo de que la estructura material del libro sea un supersignificante al servicio de la poética interna.

2.- Un contacto con la civitas hominum, simbolizada en Nueva York, que incorporará, estilizándolo o desmitificándolo el, a menudo, pésimo maquinismo de origen futurista.

3.- El hodiernismo del punto de vista.

4.- Una preocupación por lo onírico e irracional, distintos del soñar despierto, del evocar machadiano y del propio Juan Ramón anterior.

5.- Una nueva concepción del poema en prosa.

6.- La ruptura de barreras entre prosa y verso.

7.- La caricatura lírica de seres y de cosas.

8.- Una preocupación social, que ya estaba en Platero, centrada en la realidad compleja del mundo moderno y alejada ya totalmente de la bucólica y del ademán costumbrista.» 
Si a las características señaladas por Rozas añadimos que el Diario representa también el encuentro de la lírica contemporánea española con el verso libre; la apertura de la lírica española (tan dependiente durante el fin de siglo de lo francés) al influjo nuevo y fecundo -pensemos en Cernuda o en Jaime Gil de Biedma- de la literatura en lengua inglesa; $o$, para concluir con esta enumeración, la capacidad con que dota a la lengua poética para acoger, en rara mezcla de exaltación lírica y reportaje, los más diversos registros lingüísticos de nuestro idioma, entenderemos por qué no es exagerado afirmar, como el propio Rozas hizo, que en el Diario nacen el hodiernismo poético que dará sus frutos en Cántico, la semántica irracional que culminará en Poeta en Nueva York y el neopopularismo que caracteriza una parte importante de las escrituras primeras de Alberti y de Lorca. Es decir, en el Diario nacen las tres líneas más importantes en el pautado de la escritura de lo que se ha llamado «Generación del $27 »$.

No hay espacio para desarrollar ahora los tres vectores de modernidad que, tan finamente, Rozas dejó apuntados en su lectura del Diario. Me limitaré, por ello, al análisis en Juan Ramón de esa poética de la realidad que culmina en Cántico. Jaime Gil de Biedma, uno de los poetas que con mayor calado han examinado la recepción que nuestro presente ha hecho de Guillén, relatando lo que fue su juvenil experiencia de lector, confiesa:

Resultó que Cántico [...] parecía estar escrito pensando en mí. De entrada me hizo un gran servicio, que fue instalarme en el mundo habitual, hacerme abrir los ojos y mirar bien alrededor... [La palabra] objetividad se convierte [a través de la lectura de Cántico] en el sésamo maravilloso que le hará a uno salir de sí mismo. ¡Con qué alegría se descubre que, por mal que uno ande, hay cosas en este mundo que están francamente bien!

Y un poco más adelante, en relación con la escritura de Guillén, añade:

Era el terco rehusarse al propio dolor y a la propia angustia, en un intento por salvar la realidad del mundo, lo que a mí me interesaba entonces...; y no me importaba tanto la jubilosa realidad del mundo como el empeño decidido de afirmarla por encima de uno mismo (Gil de Biedma 1980, pág. 82).

«Empeño decidido de afirmar, por encima de uno mismo», la realidad del mundo. Hasta aquí la evidencia que cualquier lector de Guillén ha tenido la ocasión de experimentar. Pero Gil de Biedma, gran poeta y agudo lector, da un paso más en su interpretación guilleniana y es este nuevo paso el que ahora me interesa destacar. La poética de la realidad sobre la que se sustenta la escritura del poeta vallisoletano implica, en perfecta complementación, dos momentos: de una parte, se trata de «dejarse ganar por la presión que ejerce sobre sus sentidos la gozosa 
variedad del mundo exterior»; pero, a la vez, la poética guilleniana de la realidad exige del poeta «un simultáneo esfuerzo reflexivo que las aleja [a las cosas], las refiere en sistema o en panorama». La gozosa inmediatez con que la conciencia se abre a las cosas se complementa siempre, en la escritura de Guillén, con la reflexión que le permite referir tales cosas al haz de relaciones en que las mismas cobran sentido. Cuando el hombre, renunciando a hacer del mundo una prolongación de su individualidad, de su subjetividad, contempla las cosas como realidades diferentes a su yo, precisa construir un sistema o «panorama» de vínculos, de las cosas entre sí y de las cosas con relación a sí mismo, que haga inteligible el horizonte de realidad en que su vivir se halla instalado y que, a la vez, lo haga inteligible a él mismo, como sujeto. Gil de Biedma, mucho más claramente que yo, lo explica así:

Las cosas son definitorias: sitúan al hombre, y el hombre al situarse se entraña, toma posesión de sí mismo: gracias a que sabe qué hace y donde está sabe quién es. La realidad nos inventa gracias a las cosas... El mundo es inteligible gracias al hombre. El hombre va a su alma por las cosas, pero va a las cosas por los nombres [...], mejor dicho: ve las cosas a través de sus nombres (Gil de Biedma 1980, pág. 91).

Nombrar la realidad -y eso es la poesía para Guillén- implica invención permanente de nuevas relaciones entre el yo y las cosas, y, por tanto, redefinición y recreación permanente del universo como sistema. Nada más cierto. Pero, cuando Biedma afirma lo anterior, ¿está hablando realmente de Guillén? ¿No fue Juan Ramón, hacia 1916 -y, por tanto mucho antes de que Guillén escribiese su poemilla Los nombres- quien dejó escrito:

Creemos los nombres.

Derivarán los hombres.

Luego derivarán las cosas.

Y sólo quedará el mundo de los nombres,

letra del amor de los hombres,

del olor de las rosas.

Del amor y las rosas, no ha de quedar sino los nombres.

¡Creemos los nombres! (Jiménez 1964, pág. 287).

Pero esta es otra cuestión. Ahora estábamos hablando de vivencia -contemplación gozosa de la realidad- y de reflexión -esfuerzo que remita lo contempla-

'También el significado en que empleo el término sentido es orteguiano, véase Cerezo Galán 1984, pág. 287. 
do a un sistema-; estábamos hablando de «maravillado asombro ante la realidad» y de «reconocimiento y verificación de las cosas», las dos operaciones en que se resuelve -en la teoría y en la práctica- la poética guilleniana de la realidad. La poesía, que ante todo cumple su destino en la operación de poner nombre a las cosas, es vivencia y contemplación, pero es también conocimiento. $Y$ de nuevo nos surge la duda: ¿de quién habla Jaime Gil de Biedma? ¿De Guillén o de Ortega? Porque es Ortega, ya en Adán en el paraíso (1909), quien traza, clara y matizadamente, el sistema que Biedma reconoce en la base de la escritura guilleniana. El universo existía, parcialmente al menos, antes del sexto día de la creación, pero sólo el día sexto, cuando Adán ha acabado de poner nombres a las cosas, el universo se hace inteligible y habitable, y el hombre pasa a ocupar su lugar en el paraíso. Las coincidencias entre Ortega y la lectura que Biedma hace de Guillén son de bulto y de detalle. Los conceptos mismos de inmediatez y de reflexión, aplicados a un fenómeno cultural, proceden de Ortega (Cerezo Galán 1984, págs. 275, 277, 287), como proceden de Ortega las afirmaciones principales en que se asienta su lectura de Cántico: la interpretación del universo como red de relaciones (Gil de Biedma 1980, pág. 90); la idea de que el hombre toma posesión de sí mismo, se construye («va a su alma por las cosas»), al definir su relación con el mundo objetual que está fuera de él; es decir, al hacerse sujeto de relaciones (Gil de Biedma 1980, pág. 91).

El mayor acierto de Biedma, en su lectura de Guillén, tiene su origen en la epistemología de Ortega, aunque el poeta catalán en ningún momento de su ensayo (creo) cite explícitamente a Ortega. Es el pensamiento de Ortega el que, ciertamente, hace posible la poética de la realidad a la que tan acertadamente responde la escritura poética de Guillén. Su grito de combate, ya lo conocemos, no podía ser más claro: «Salvémonos en las cosas del naufragio de lo íntimo».

Sin ninguna duda, la base de la poética de la realidad que la crítica ha reconocido en la escritura guilleniana, tiene su origen en Ortega y en el empeño de este por liberar el pensamiento español de la atrofia subjetivista. El idealismo que está en la base de todo subjetivismo suplanta -si empleamos una terminología que Schopenhauer había canonizado- la presencia del mundo por su representación. En el idealismo postkantiano ${ }^{2}$, tan operativo en la literatura española del fin de siglo, se afirma «que a la conciencia sólo le son dados sus estados subjetivos o ideas. En tal caso, los objetos sólo tienen realidad en cuanto son ideados por el sujeto individual o abstracto» (Ortega 1946, IV, pág. 39). La realidad acaba siendo suplantada por la idea y el mundo se espectraliza. El nietzscheano «baile de

El origen está en Descartes, Cerezo Galán 1984, págs. 270, 274, 269. 
las máscaras», que tan acertadamente refleja el poema «Fantasía de una nota de abril» de Antonio Machado, reemplaza a la vida real. Las consecuencias ya las conocemos por el poema de Arias tristes, que anteriormente cité: «cuando el hombre se queda o cree quedarse solo, sin otra realidad, distinta de sus ideas, que le limite crudamente, pierde -diagnostica Ortega- la sensación de su propia realidad, se vuelve ante sí mismo entidad imaginaria, espectral, fantasmagórica» (Ortega 1946, VI, págs. 47-48). El morbo subjetivista, sin embargo, tiene una terapia muy precisa: volcarse sobre las cosas:

Sólo bajo la presión formidable de alguna trascendencia -afirma el filósofo- se hace nuestra persona compacta y sólida y se produce en nosotros una discriminación entre lo que, en efecto, somos y lo que meramente imaginamos ser (Ortega 1946, VI, págs. 47-48).

Y, en otro lugar, añade:

Nuestro ser consiste por lo pronto en tener que estar en la circunstancia. De ahí que la ocupación con nuestro ser, el hacernos cuestión de él, lleva consigo el hacernos cuestión de lo que nos rodea y envuelve (Ortega 1981a, pág. 122).

Ser - Ortega prefiere casi siempre hablar de vivir- es gozosa apertura a la circunstancia, es emocionada y frenética apertura a las cosas. Pero conviene precisar algo que, aunque está implícito en todo lo que he dicho, no debe olvidarse; y, de nuevo, Ortega resulta de extraordinaria ayuda para hacernos recordar. No basta la entrega gozosa a las cosas, pues «el ser carece de sentido fuera de su mutualidad con el conocer; y... por tanto, tiene también que someterse a las condiciones de éste. La correlación es estricta; ambos términos viven el uno del otro sin primicia alguna. Cierto; porque hay ser hay conocimiento. Pero la viceversa es también forzosa: porque hay conocer hay ser» (Ortega 1981b, pág. 209). No basta el goce sensitivo de la realidad; la realidad no se nos ofrece en plenitud -es una de las grandes experiencias relatadas en el Diario- hasta que no es capaz de «elevarse hasta su nombre», hasta que no se convierte en acto de cultura. No basta el mero afirmarse de las cosas en su realidad apariencial; es preciso dotarlas de sentido. La dimensión vivencial reclama la reflexiva. Las cosas, cuando se inscriben en la circunstancia de una vida, se convierten en materiales de cultura y «el acto específicamente cultural -afirma Ortega- es el creador, aquél en el que extraemos el logos de algo que todavía era insignificante» (Ortega 1946, I, pág. 321). Pero todavía es más claro otro texto que no quiero dejar de citar: «dado un hecho -un hombre, un libro, un paisaje, un error, un dolor- llevarlo por el camino más corto a la plenitud de su significado. Colocar la materia de todo orden, que la vida, en su resaca perenne, arroja a nuestros pies como restos inhábiles de 
un naufragio, en postura tal que dé en ellos el sol innumerables reverberaciones» (Ortega 1946, I, pág. 311). Inmediatez de lo vital que reclama la reflexión; vida con vocación de hacerse cultura, da igual el termino que utilicemos, porque ambos conducen al mismo binomio desde el que Jaime Gil de Biedma construye su lectura de Guillén.

Creo que es en esta perspectiva en la que efectivamente debe leerse a Guillén; y, desde luego, es en esta perspectiva en la que Jaime Gil de Biedma, sin confesarlo nunca, elabora su lectura, espléndida lectura, de Guillén. Pero no es superfluo recordar que la relación Ortega-Guillén constituye en realidad un triángulo, uno de cuyos vértices, histórica y conceptualmente, pasa por Juan Ramón y pasa, muy especialmente, por la actitud estética y mental que hace posible el Diario. En efecto, si prestamos atención a los textos que integran el libro juanramoniano, lo primero que llama la atención es el tremendo esfuerzo del poeta por abrirse a la realidad del mundo, rompiendo con el subjetivismo de su obra anterior. En el Diario, el mundo rezuma sentido por todos sus poros. «El descubrimiento de lo otro y de los otros es tan visible -afirma Aurora de Albornoz-que, a veces, llegamos a pensar que hay un olvido del yo» (Jiménez 1973, pág. 51). Esta radical apertura a la «otredad» es lo primero que sorprende al lector del Diario, pero al crítico, con ser esa una cuestión importante, le puede interesar más todavía el examen de las pautas conceptuales sobre las que tal apertura se sustenta. $Y$, en este sentido, el prologuillo que antecede a los poemas resulta extremadamente valioso. En él, Juan Ramón formula algunos presupuestos, que serán esenciales para orientar correctamente la lectura de esa «apertura a la realidad», que iluminan los textos del Diario. Merece la pena que acudamos a las palabras exactas del poeta:

1.- «En este album de poeta copié, en leves notas, unas veces con color sólo, otras sólo con pensamiento, otras con luz sola, siempre frenético de emoción, las islas que la entraña prima y una del mundo del instante subía a mi alma» (Jiménez [1917] 1998, pág. 98). Es decir, en la terminología con que Biedma lee a Guillén, inminencia.

2.- «La depuración constante de lo mismo, sentido en la igualdad eterna que ata por dentro lo diverso en un racimo de armonía sin fin» (Jiménez [1917] 1998, pág. 98). Es decir, en la misma clave terminológica anterior, reflexión, que permite traducir la «emoción frenética» del «instante», gozo de la contemplación, a un sistema en el que se hace visible «la entraña prima y una del mundo», en que «lo diverso» se reconcilia. 
Desde estas palabras liminares, el viaje que es el Diario se nos ilumina como lo que realmente es: una aventura de contemplación y de conocimiento, que necesariamente concluye con la emergencia de un yo, como conciencia, en el que nos cuesta (nos cuesta a nosotros, pero también le cuesta al propio poeta) reconocer al soñador, que había estampado su firma al frente de libros como Arias tristes. El poema «Ausencia de un día», así como el que con el título «Mar» lleva el número CLXI en el poemario, son -en relación de oposición con el poema «Menos» (XXXIX)- reveladores al respecto:

AHORA, soñar es verte, y ya, en vez de soñar, vivir será mirar tu luz, hasta la muerte.

¡Mirar tu luz! Ni sueño, ni ensueño. Sólo amor, más fácil y mejor que el sueño y el ensueño.

¡Muera mi fantasía!

Tocar, gustar, oler, oír, ver... esclarecer tu verdad con la mía; pues que tú me has dejado, con tu oculto fluir, para tu sonreír como un iluminado.

¿Qué claros campos riegas, derecho, oh río, hoy! ¿Ahora sí que voy por las eternas vegas!

«Ni sueño, ni ensueño», tan sólo «tocar, gustar, oler, oír, ver... esclarecer tu verdad con la mía». Si en el Diario no faltan los momentos negativos, de insatisfacción y de oquedad, el predominio de los momentos de afirmación, sobre los de negación, es absoluto. El resultado de esta actitud -tan nueva en Juan Ramón- no puede ser ni más positivo, ni más claramente expresado:

A veces, creo que despierto

de mi misma vigilia, y que con ella

-sueño del mediodíase van monstruos terribles del horizonte puro. 
-Es cual una tormenta de duermevela, cuyo trueno no se supiera nunca si fue verdad o fue mentira.-

Se me abre el corazón y se me ensancha como el mar mismo. La amenaza huye por el oriente a sus pasadas nubes.

El mar sale del mar y me hace claro (Diario, CLXI).

«El mar sale del mar y me hace claro». Solo al enfrentarse con el mundo, y abandonar las «representaciones» de sueños y ensoñaciones, el yo adquiere conciencia, clara y distinta, de su radical mismiedad. Pero para llegar hasta aquí era preciso un largo viaje, que conviene revisar desde el principio, en sus diferentes etapas. Los poemas iniciales del libro cantan el esfuerzo de la conciencia del poeta, «salida ahora de tu sueño, nueva,/ tierna, casi sin luz ni color aún» («La Mancha», V), por ajustar su mirada a la realidad recien descubierta. El mar real («Soledad», XXIX), en lucha todavía con el «el mar de mi imaginación» («Menos», XXXIX), hace imposible todavía el nacimiento de Venus («Venus», XXXI). El milagro parece inminente, pero la verdad es aún «verdad sin realidad":

¡VA a nacer también aquí y ahora! Vedlo. Nácares líquidos. Las sedas, las caricias, las gracias todas, hechas ola de espuma... ¡Ya!...jAllí!... ¿No?... ¿Será culpa del fraile?

¡Da ganas de llorar que el barco, ¡el oso este!, pose así, negro y sucio, sobre el agua, esa espalda de ternura! i A ver! ¿Que quiten de aquí el barco, que va a nacer Venus! -¿Y dónde lo ponemos? ¿Y dónde lo ponemos?-

¡Apolo, amigo sólo de la diosa, que vas mientras tocan aquí al rosario, con tu ramo grana -blanco en la aurora, de oro al mediodía-, a tu casa del poniente! ¡Apolo, amigo sólo mío; Venus murió sin nacer, por culpa de la Trasatlántica! (Diario, XXXI).

Sólo avanzado el viaje, ya por mar, el prodigio se produce y la mundo se revela en toda su plenitud. La realidad «se eleva hasta su nombre»:

Te tenía olvidado, cielo, y no eras más que un vago existir de luz, visto -sin nombrepor mis cansados ojos indolentes. Y aparecías, entre las palabras 
perezosas y desesperanzadas del viajero, como en breves lagunas repetidas de un paisaje de agua visto en sueños...

Hoy te he mirado lentamente, y te has ido elevando hasta tu nombre (Diario, XLIII).

Y lo mismo ocurre con el mar. Toda la realidad está volcada en un dinamismo que no tiene otro objeto que dar muestra de su afán por revelarse y hacerse inteligible:

NO sé si es más o menos. Pero sé que el mar, hoy, es el mar. Como un orador sin paz, que un día llega a su plena exaltación, y es él ya para siempre, porque la ola de su fervor rompió su vaso, así, hoy, el mar; como un pintor que acertase a dar en una sola pincelada la luz del color de la aurora primera; como un poeta que se hace en su alma una estrofa mayor que el mundo, así, hoy, el mar; como una primavera que abre su flor mayúscula...

Hoy el mar ha acertado, y nos ofrece una visión mayor de él que la que teníamos de antemano, mayor que él hasta hoy. Hoy le conozco y le sobreconozco. En un momento voy desde él a todo él, a siempre y en todas partes él.

Mar, hoy te llamas mar por vez primera. Te has inventado tú mismo y te has ganado tú solo tu nombre, mar (Diario, CLXVI).

Pero la revelación no se da de una vez por todas, sino que sólo en breves instantes de luz alcanza la plenitud y se hace nombre. A veces, la realidad se torna opaca ${ }^{3}$ :

DE pronto, esta conciencia triste

de que el mar no nos ve; de que no era

esta correspondencia mantenida

días y noches por mi alma

y la que yo le daba al mar sin alma, sino en un amor platónico.

ciego!

¡Sí, inmensamente

${ }^{3}$ Por respeto a la terminología poética juanramoniana opongo realidad plena a realidad opaca. Pero ambos conceptos responden literalmente a la oposición que Ortega hace entre realidad primaria (la de las cosas cuando no pensamos en ellas, cuando no las convertimos en parte de nuestra vida) y realidad pensada (las cosas, cuando las incorporamos a esa realidad, que es la vida). Véase, por ejemplo, Unas lecciones de metafisica (Ortega 1981 a, pág. 82). Véase también P. Cerezo Galán 1984, pág. 314. 
Aunque esta luna llena y blanca

nos alumbre, partimos las espalda del agua en una plenitud de oscuridades

Y no vistos del mar, no existimos por este mar abierto que cerca nuestra nada de horizontes verdes, resplandecientes e ideales.

Este miedo, de pronto... (Diario, CLXXXIX).

En estos momentos, las amarras tendidas por el yo a las cosas se rompen, como dan cuenta los poemas XLIV («iNo!»), LX («Skay») de manera que la crónica (es el caso de las prosas «Túnel ciudadano», «Iglesias» o «El prusianito») sustituye al poema:

EL mar dice un momento

que sí, pasando yo.

$Y$ al punto,

que no, cien veces, mil

veces, hasta el más lúgubre infinito.

No, ¡no!, ¡¡no!!, i¡¡no!!!. cada vez más

fuerte, con la noche...

Se van uniendo

las negaciones suyas, como olas, ¡no, no, no, no, no, no, no, no, no, no!-

y, pasado, todo él, allá hacia el este,

es un inmenso, negro, duro y frío

¡no! (Diario, XLIV).

La escritura, entonces, deja de ser una forma de profundizar en la esencia constitutiva de las cosas, una forma de crear entramados de sentido que hagan inteligible el universo, para convertirse, sólo, en vehículo descriptivo de su exterioridad:

BROADWAY. La tarde. Anuncios mareantes de colorines sobre el cielo. Constelaciones nuevas. El Cerdo, que baila, verde todo, saludando con su sombrerito de paja, a derecha e izquierda. La Botella, que despide, en muda detonación, su corcho colorado, contra un sol con boca y ojos. La Pantorrilla eléctrica, que baila sola y loca, como el rabo separado de una salamanquesa. El Escocés, que enseña y esconde su whisky con reflejos blancos. La Fuente, de aguas malvas y naranjas, por cuyo chorro pasan, como en una culebra, prominencias y valles ondulantes de sol y luto, eslabones de oro y hierro (que trenza un chorro de luz y otro de sombra...). El Libro, que ilumina y apaga las imbecilidades sucesivas de su dueño. El Navío, que, a cada instante, al encen- 
derse, parte cabeceando, hacia su misma cárcel, para encallar al instante en la sombra... Y...

- ¿La luna! - ¿A ver? -Ahí, mírala, entre esas dos casas altas, sobre el río, sobre la octava, baja, roja, ¿no la ves...? -Deja, ¿a ver? No... ¿Es la luna, o es un anuncio de la luna? (Diario, CXI).

La pugna de la realidad por revelarse en toda su plenitud y la pugna del yo por hacer inteligible esa revelación, nombrándola, es la gran aventura que canta el Diario juanramoniano. Y en tal pugna, ambas realidades, el yo y las cosas, son imprescindibles. En palabras de Ortega, que resultan un extraordinario colofón al viaje del Diario, «el mundo exterior no existe sin mi pensamiento» que lo crea al nombrarlo; pero mi pensamiento y el mundo no se confunden: «el mundo exterior no es mi pensamiento; yo no soy teatro ni mundo -soy frente a ese teatro, soy con el mundo-. somos el mundo y yo» (Ortega 1946, VII, págs. 401-402).

El Diario es, como ha estudiado Miguel Ángel Pérez Priego, un libro de viaje y un diario. Pero es, por encima de todo ello, el testimonio grandioso de una aventura, en la que el yo, abandonadas las «representaciones» que en su conciencia habían reemplazado hasta ese momento al mundo, se abre a la realidad con avidez de conocimiento. En el Diario hay una dimensión existencial y, en los poemas en que tal dimensión se hace presente, se percibe claramente la punga del yo por «salvarse en las cosas del naufragio de lo íntimo»; pero, sobre esta dimensión, hay otra dimensión metafísica, que convierte la escritura del Diario en fundación ontológica de la realidad.

El libro juanramoniano es importante, muy importante, en sí mismo, pero lo es también por lo que representa, en cuanto aclimatación de una poética de la realidad, que es la que hará posible, por ejemplo, el fenómeno Guillén. Juan Ramón no hablará de poética de la realidad. Hablará de la poética de la desnudez, pero en ambos la verdad última es, esencialmente, la misma. Uno y otro camino, a donde conducen es a la liberación de cualquier concesión o ataduras a lo literario (ropajes) y a la inauguración de una mirada personal sobre las cosas. En la base de ambos caminos, ya lo he señalado con reiteración, está Ortega, que, en ¿Qué es la filosofía?, afirma con rotundidad: «lo que me es dado es mi vida, no mi yo solo, ni mi conciencia hermética... Me es dada mi vida, y mi vida es ante todo un hallarme yo en el mundo» (Ortega 1946, VII, pág. 404). Desde esta afirmación ("mi vida es un hallarme yo en el mundo») se entiende que, en plena vigencia de la poesía social, en los duros y comprometidos años del compromiso, un poeta a la moda convierta a Ortega, aunque de manera un tanto clandestina, en instrumento para la canonización (de canon estético, por supuesto) de 
Guillén. Pero muchos antes de que Ortega hiciese la afirmación, que acabo de citar, Juan Ramón, el contra-modelo -según una parte importante de la crítica- de esta misma poesía, había escrito: «La que viaja, siempre que viajo, es mi alma entre almas».

\section{BIBLIOGRAFÍA}

Cerezo Galán, Peđro. 1984. La voluntad de aventura, Barcelona, Ariel

GIL DE BIEDMA, Jaime. 1980. El pie de la letra, Barcelona, Crítica

JimÉnEZ, Juan Ramón. 1964. Libros inéditos de poesía, Madrid, Aguilar.

- 1967. Primeros libros de poesía, ed. de Francisco Garfias, Madrid, Aguilar.

- 1973. Nueva antolijía, ed. de Aurora Albornoz, Barcelona, Ediciones Península.

- [1917] 1982. Diario de un poeta recién casado, ed. Ricardo Gullón, Madrid, Taurus.

- [1917] 1998. Diario de un poeta recién casado, ed. de Michael P. Predmore, Madrid, Cátedra.

Ortega y Gasset, José. 1946. Obras completas, Madrid, Revista de Occidente.

- 1981a. Unas lecciones de metafísica, Madrid, Revista de Occidente.

- 1981b. Investigaciones psicológicas, Madrid, Revista de Occidente.

PÉrez PrIEgo, Miguel Ángel. 1981. «El género literario de Diario de un poeta reciencasado», en Juan Ramón Jiménez en su centenario, Cáceres, Ministerio de Cultura.

Rozas, Juan Manuel (1981). «Juan Ramón y el 27. Hodiernismo e irracionalismo en la parte central del Diario», en Juan Ramón Jiménez en su centenario, Cáceres. 